\title{
Efficient light harvesting in deep-water zooxanthellate corals
}

\author{
Samuel E. Kahng ${ }^{1, *}$, Eric J. Hochberg ${ }^{2}$, Amy Apprill $^{3}$, Daniel Wagner ${ }^{4}$, \\ Daniel G. Luck ${ }^{1}$, Denise Perez ${ }^{5}$, Robert R. Bidigare ${ }^{6}$
}

\author{
${ }^{1}$Hawai${ }^{1}$ Pacific University, 41-202 Kalaniana`ole Highway, Waimanalo, Hawai'i 96795, USA \\ ${ }^{2}$ Bermuda Institute of Ocean Sciences, 17 Biological Station, St. George's GE 01, Bermuda \\ ${ }^{3}$ Woods Hole Oceanographic Institution, 266 Woods Hole Road, Woods Hole Massachusetts 02543-1050, USA \\ ${ }^{4}$ Papahānaumokuākea Marine National Monument, 6600 Kalaniana'ole Highway, Suite 300, Honolulu, Hawai'i 96825, USA \\ ${ }^{5}$ National Coral Reef Institute, Nova Southeastern University, 8000 North Ocean Drive, Dania Beach, Florida 33004-7796, USA \\ ${ }^{6}$ University of Hawai'i at Mānoa, 1000 Pope Road, Honolulu, Hawai'i 96822, USA
}

\begin{abstract}
The vertical zonation of dominant megabenthic, photosynthetic taxa suggests that differential photosynthetic capabilities enable specialized, low-light zooxanthellate corals to dominate at depths where shallow-water corals become light limited. This study examines the ecophysiology of deep-water (68-113 m) Leptoseris spp. and shallow-water (2-15 m) Porites spp. zooxanthellate corals from Hawai'i by comparing spectral absorbance properties and photosynthetic pigment concentrations to the available light spectra in their respective environments. Photosynthetically active radiation reaching Leptoseris spp. was 3 to $11 \%$ of surface irradiance compared to 41 to $90 \%$ reaching Porites spp. Optical measurements indicated that Leptoseris spp. exhibited lower reflectance (i.e. higher absorptance) compared to Porites spp. and were chromatically adapted to the wavelengths of photons available at depth. Despite the decreased spectral reflectance, deep-water Leptoseris spp. exhibited significantly lower areal photosynthetic pigment concentrations than did shallow-water Porites spp. Based on morphological comparisons of the skeletons of both coral genera, we hypothesize that Leptoseris spp. skeletons may cause incident light to travel through the coral tissue several times, thereby increasing photon-pigment interactions without increasing pigment concentrations. This superior light harvesting efficiency exhibited by Leptoseris in an energy limited environment (enabled by skeletal design rather than pigment physiology) may in part explain why the dominant genus of reef-building corals in Hawai'i cannot compete successfully with specialized low-light corals at extreme depths.
\end{abstract}

KEY WORDS: Photobiology $\cdot$ Mesophotic $\cdot$ Coral ecology $\cdot$ Ecophysiology $\cdot$ Leptoseris Resale or republication not permitted without written consent of the publisher

\section{INTRODUCTION}

Zooxanthellate scleractinian corals are keystone species in well-lit tropical and subtropical waters where they create massive geological structures and provide critical habitat for a diverse abundance of reef fish and invertebrates (Birkeland 1997). While typically studied within the depth range of recreational SCUBA diving $(<40 \mathrm{~m})$, light-dependent coral reef ecosystems extend far below these depths (Hin- derstein et al. 2010). In clear oligotrophic waters, zooxanthellate corals can form large aggregations below $100 \mathrm{~m}$, with individual colonies growing at depths >150 m (Maragos \& Jokiel 1986, Kahng \& Maragos 2006, Kahng \& Kelley 2007). In the ocean, downwelling light attenuates exponentially with increasing depth (Kirk 1994). At the lower distributional limit of zooxanthellate corals, the available photosynthetically active radiation (PAR) can be $<1 \%$ of that in shallow water (Kahng et al. 2010). 
Coral community structure changes considerably with increasing depth. Zooxanthellate coral taxa which dominate shallow-waters (e.g. Acropora, Pocillopora, and Porites) are often rare or conspicuously absent in the lower photic zone (Kahng et al. 2010). With increasing depth, growth rates of dominant, shallow-water corals often decrease due to lightlimitation (Huston 1985; Grigg 2006). In the lower photic zone, zooxanthellate coral taxa such as Leptoseris, which are cryptic and rare in shallow-water (Dinesen 1983), can become abundant and often dominate the coral fauna (Kahng et al. 2010).

This pattern of coral distribution and abundance with depth suggests that each coral species may have an optimal depth (Falkowski et al. 1990, Hoogenboom et al. 2009). Additionally, certain photosynthetic taxa may be differentially adapted to deep water where ambient light levels are too low to support their shallow-water counterparts. There are multiple non-exclusive hypotheses which can explain how some zooxanthellate coral taxa adapt and thrive at extreme depths: (1) energetic requirements are reduced via decreased biomass, metabolism, and growth rates; (2) rates of heterotrophy are elevated compared to autotrophy; and (3) adaptations enable increased photosynthetic efficiency under low-light conditions.

Reduced metabolism is a common adaptation for deep-sea organisms with limited food availability (Gage 2003), and multiple lines of evidence suggest that reduced energetic requirements (e.g. slower growth, lower tissue biomass, and weaker calcification) apply to zooxanthellate corals in the lower photic zone (reviewed by Kahng et al. 2010). In contrast, evidence to date is mixed on whether zooxanthellate corals increase their reliance on heterotrophy with increasing depth (Muscatine et al. 1989, Mass et al. 2007, Alamaru et al. 2009, Einbinder et al. 2009, Lesser et al. 2010).

A number of adaptations facilitating increased photosynthetic efficiency under low-light conditions have been previously recognized in zooxanthellate corals. Corals acclimatized to low-light regimes (i.e. shade adapted) can exhibit one or more of the following characteristics: flattened plate-like or encrusting morphologies which reduce self-shading and maximize capture of downwelling light (Kühlmann 1983, Anthony et al. 2005); a mono-layered cellular arrangement of zooxanthellae which minimizes selfshading of light harvesting centers (Dustan 1979, Schlichter et al. 1986); higher pigment concentrations (per cell and per unit surface area) via increase in number and size (absorption cross section) of the photosynthetic units (PSU) (Falkowski \& Dubinsky 1981, Kirk 1994); maximum rates of gross photosynthesis $\left(P_{\max }\right)$ at lower irradiance levels (Falkowski et al. 1990); and higher photosynthetic efficiency per unit biomass (Anthony \& Hoegh-Guldberg 2003). For zooxanthellate corals in the lower photic zone, evidence suggests that some subclades of Symbiodinium are adapted to low-light environments while others appear to be depth generalists occurring in hosts across a wide range of light conditions (reviewed in Baker 2003, Kahng et al. 2010).

Researchers have long recognized the importance of photosynthetic pigments to coral ecology, and there have been several investigations into environmental controls on pigment concentrations and metabolic parameters (Falkowski \& Dubinsky 1981, Dustan 1982, Brown et al. 1999b, Fitt et al. 2000, Lesser 2000). The photoautotrophic dinoflagellates (i.e. Symbiodinum spp.) contained within the tissues of most hermatypic corals are responsible for the high rates of gross primary production observed in coral reef communities (Muscatine 1990). Zooxanthellae have the major photosynthetic pigments chlorophyll a ( $\mathrm{chl} a$ ), chlorophyll $C_{2}\left(\mathrm{chl} C_{2}\right)$, peridinin, diadinoxanthin, diatoxanthin, dinoxanthin, and $\beta$-carotene (Jeffrey \& Haxo 1968, Brown et al. 1999a). Chlorophylls $a$ and $c_{2}$, along with peridinin, are complexed to protein and serve as major light-harvesting components. $\beta$-carotene residing with chl $a$ also functions in photosystem I (Kirk 1994). $\beta$-carotene, diadinoxanthin, diatoxanthin, and dinoxanthin have photoprotective functions in zooxanthallae (Falkowski \& Laroche 1991, Kirk 1994, Brown et al. 1999a).

In general, concentrations of light-harvesting pigments per unit area increase as growth irradiance (i.e. the average irradiance in which an organism is growing) decreases while concentrations of photoprotective pigments show the opposite trend (Falkowski \& Dubinsky 1981, Dubinsky \& Stambler 2009). Concomitant with this increase in total light-harvesting pigments, there is a relative enrichment of accessory pigments like peridinin in relation to $\mathrm{chl}$ a (IglesiasPrieto \& Trench 1994). However, this general pattern of shade acclimatization in corals is not always evident with increasing depth (e.g. Wyman et al. 1987). For Leptoseris fragilis in the lower photic zone, Fricke et al. (1987) found that in situ pigment concentration decreased with depth across its natural depth range from 100 to $135 \mathrm{~m}$. Although higher concentrations of photosynthetic pigments can increase utilization of ambient light, photosynthetic efficiency per unit of pigment decreases due to self-shading of PSUs (Falkowski et al. 1990). Higher pigment concentra- 
tions require more resource investment and may not be an effective strategy for photosynthetic organisms adapting to low energy environments at depth (Enriquez et al. 2005, Stambler \& Dubinsky 2007).

The highly reflective calcium carbonate skeletons of zooxanthellate corals enhance the light collection efficiency of symbiont pigments, and light harvesting is thought to be a driving force in the evolution of scleractinian coral skeletons (Kuhl et al. 1995, Enriquez et al. 2005). Intra-species variations in colony geometry correlate to ambient light levels and serve to regulate light capture by maintaining near optimal internal irradiance across a wide range of light regimes (Anthony et al. 2005). Colonies growing under excessive irradiance form morphologies with high levels of self-shading while colonies growing under less light form morphologies with progressively less self-shading (Kaniewska et al. 2008). The trade-off between enhancing light harvesting under suboptimal

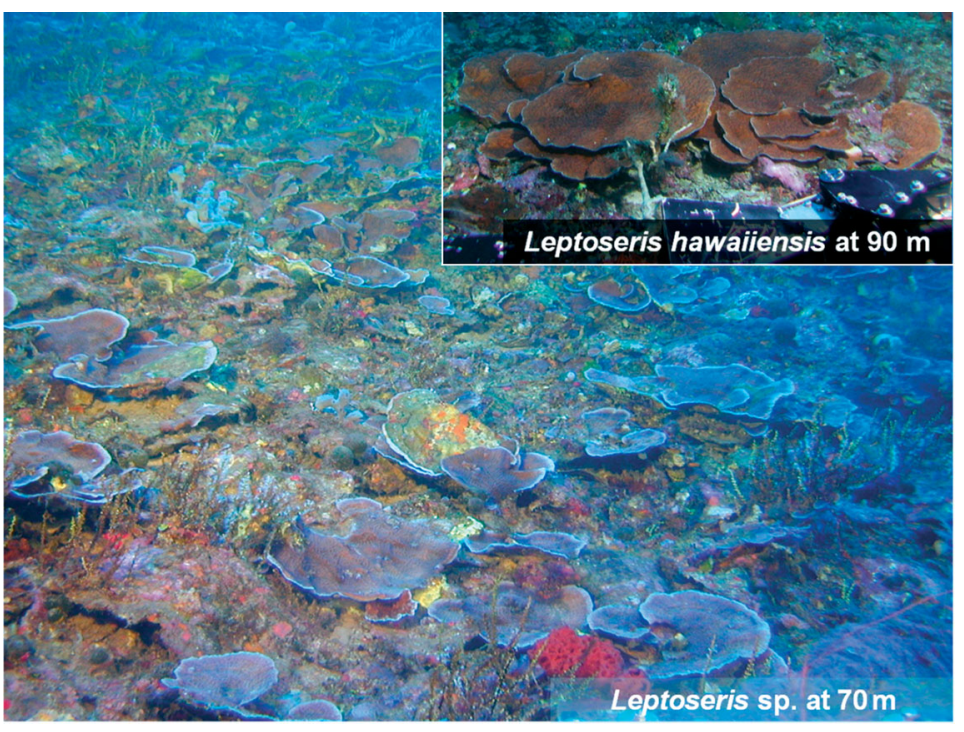

Fig. 1. A large field of deep-water Leptoseris sp. colonies intermixed with the invasive octocoral Carijoa sp., at $\sim 75 \mathrm{~m}$ depth in the Au'au Channel between the Hawai'ian islands of Maui and Lāna'i. Inset: large colonies of Leptoseris hawaiiensis at $~ 90 \mathrm{~m}$ in the Au'au Channel where colonies can grow to $>1 \mathrm{~m}$ in diameter. Photos courtesy of the Hawai'i Undersea Research Laboratory (HURL)

(HURL) manned-submersible 'Pisces IV' on October 22 to 26, 2006. Leptoseris specimens were collected in the Au'au Channel, Hawai'i, at depths ranging between 68 to $113 \mathrm{~m}$ and included L. hawaiiensis, L. scabra and other unidentified Leptoseris spp. Efforts to revise the taxonomy and phylogeny of deep-water Leptoseris in Hawai'i are underway but not yet complete (D. Luck pers. comm.). For the purposes of this study, these deep-water specimens will be collectively called Leptoseris. Fragments of 9 Leptoseris colonies were collected for pigment analysis and frozen at $-80^{\circ} \mathrm{C}$ immediately following collection. Ten live Leptoseris colonies were placed in an isolated culture of low intensity blue light ( $\mathrm{T}-12$, 40 Watt, 48' Coralife Actinic 03-blue fluorescent bulbs) at the Waikiki Aquarium in Honolulu, Hawai'i. PAR irradiance of the holding tanks was 5 to 37 mol photons $\mathrm{m}^{-2} \mathrm{~s}^{-1}$, and coral placement was arranged to roughly match in situ light levels from their respective depths. On 9 April 2008, fragments from the 10 live colonies in culture were sampled for pigment analysis and frozen at $-80^{\circ} \mathrm{C}$ immediately following collection.

Using methods described in Hochberg et al. (2006), 36 colonies of Porites lobata $(\mathrm{n}=22)$, P. lutea $(\mathrm{n}=12)$, and $P$. compressa $(\mathrm{n}=2)$ were sampled for in situ reflectance spectra and cored (6 $\mathrm{mm}$ diameter) for post-collection pigment measurements at 2 to $15 \mathrm{~m}$ in Kaneohe Bay during April and August 2004. Coral
A total of 19 Leptoseris colonies were collected using the Hawai'i Undersea Research Laboratory

\section{Study sites and sample collections}


samples were wrapped in aluminum foil and placed on ice in the dark for $3 \mathrm{~h}$, transferred to a $-50^{\circ} \mathrm{C}$ freezer for $2 \mathrm{wk}$, and then immersed in liquid nitrogen for 2 mo prior to pigment measurements.

\section{Measurements of downwelling light}

Using the methods described in Kahng \& Kelley (2007), the spectral diffuse attenuation coefficient for downwelling plane irradiance, $K_{\mathrm{d}}(\lambda)$, was measured in 2 contrasting types of water. Nearshore coastal water $(\sim 1.6 \mathrm{~km}$ from shore) was sampled adjacent to shallow-water coral reefs dominated by Porites spp. on south Oahu (21⒖64'N, $\left.157^{\circ} 50.25^{\prime} \mathrm{W}\right)$ on 26 May 2005. Offshore oligotrophic water representative of that overlying the deep reef in the Au'au Channel was sampled at a site $40 \mathrm{~km} \mathrm{NW}$ of the Au'au Channel in the Kalohi Channel $\left(21^{\circ} 2.60^{\prime} \mathrm{N}, 157^{\circ} 11.04^{\prime} \mathrm{W}\right)$ between Lāna'i and Moloka'i on 26 October 2006. At each location, a PRR-800 dropsonde radiometer (Biospherical Instruments) was deployed and spectral downwelling plane irradiance $\left(\mathrm{W} \mathrm{m}^{-2} \mathrm{~nm}^{-1}\right)$ sampled at $10 \mathrm{~Hz}$ on 19 channels $(380-710 \mathrm{~nm})$ in free-fall mode $\left(\sim 0.75 \mathrm{~m} \mathrm{~s}^{-1}\right)$. PAR was calculated as the integral with respect to wavelength of spectral irradiance. The attenuation coefficient for PAR, $K_{\mathrm{d}}(\mathrm{PAR})$, was calculated based on nonlinear, least squares (Gauss-Newton) regression to the expected exponential decay with depth.

\section{Skeletal preparation and analysis}

Corals were bleached using 2 iterations of soaking in $\sim 6 \%$ sodium hypochlorite for $24 \mathrm{~h}$ and vigorous rinsing and soaking in tap water for $24 \mathrm{~h}$. Skeletons were air dried at $100^{\circ} \mathrm{C}$ in an oven for $\sim 1$ hand cooled to room temperature overnight. Coral skeletons that retained any non-white discoloration after bleaching were not used in subsequent optical measurements. Bleached skeletal samples of shallowwater Porites spp. (P. lobata, P. lutea, and P. compressa) ( $\mathrm{n}=10$ ) and deep-water Leptoseris spp. ( $\mathrm{n}=$ 10) were examined under a Nikon SMZ800 dissecting microscope.

Cross-sections of skeletal samples $(\sim 5$ to $20 \mathrm{~cm})$ were cut parallel to the angle of incident light with a rock saw and sanded and polished with a Dremmel tool to qualitatively examine the 3-dimensional geometry of the coral surface exposed to incident light. Thin cross-sections of 2 Leptoseris and 2 Porites samples were prepared for scanning electron microscopy (SEM) by rinsing in commercial bleach for $2 \mathrm{~min}$, transferring to $100 \%$ ethanol for $1 \mathrm{~h}$, and air-drying overnight. Samples were mounted onto standard SEM stubs using carbon paste and goldpalladium coated using a 6.2 Hummer Sputtercoater. To illustrate the depth of skeletal features such as height of septo-costae and depth of calices, specimens were viewed and photographed using a Hitachi S-4800 field emission scanning electron microscope at the University of Hawai'i Biological Electron Microscope Facility.

\section{Pigment measurements}

Using high performance liquid chromatography (HPLC) and following the methods in Apprill et al. (2007), flat fragments of Leptoseris $(\mathrm{n}=19)$ and cores of Porites $(\mathrm{n}=36)$ were analyzed to measure concentrations of the following photosynthetic and photoprotective pigments: monovinyl chlorophyll a (chl a), monovinyl chlorophyll $b(\mathrm{chl} b)$, chlorophyll $c_{2}\left(\mathrm{chl} c_{2}\right)$, peridinin, $\beta$-carotene, fucoxanthin, diadinoxanthin (DDX), diatoxanthin (DTX), and dinoxanthin (DINO). Surface area measurements for the irregularly shaped Leptoseris fragments were made using calibrated, digital photography with the software program Coral Point Count with Microsoft Excel extensions (Kohler \& Gill 2006).

For samples containing chl $b$, an endolithic pigment not produced by the dinoflagellate symbionts, the source of chl a was differentiated between symbiont derived and non-symbiont derived following the methods in Apprill et al. (2007). A chl $b$ :a ratio of 0.79 was applied to estimate the chl a contribution from endolithic algae (Jeffrey \& Haxo 1968). The endolithic algae chl a contribution was then subtracted from the total chl a to obtain the dinoflagellate endosymbiont contribution.

Pigment concentrations from 10 cultured Leptoseris colonies were compared to 9 samples frozen immediately after original collection to assess whether aquarium light environment (modeled after in situ conditions) influenced pigment concentrations and ratios and to confirm that storage time of the frozen samples (16 mo) did not have deleterious effects on pigment photosynthetic concentrations, as predicted by Sosik (1999). For each pigment measured, a 1-way ANOVA was performed between the 2 groups of Leptoseris samples. For each pigment concentration and ratio, a 1-way ANOVA was also performed between Porites and Leptoseris. 


\section{Spectral reflectance measurements}

Prior to sampling the 10 Leptoseris colonies in culture at the Waikiki Aquarium for pigment analyses, spectral reflectance, $R$, for visible wavelengths (400-700 nm) was measured. Similarly, $R$ for shallow-water samples of Porites $(\mathrm{n}=36)$ was measured in situ prior to sampling for pigment analyses. $R$ was measured using the detailed methods in Hochberg \& Atkinson (2000) and Hochberg et al. (2006).

The measurement system consisted of a fiber optic cable attached to an Ocean Optics USB2000 portable spectrometer (wavelength range 330-850 nm, with $\sim 0.3 \mathrm{~nm}$ sample interval and $\sim 1.3 \mathrm{~nm}$ optical resolution, wavelengths calibrated to Ocean Optics HG-1 Hg-Ar lamp), which in turn was operated with a palmtop computer. In order to measure the properties of the coral surface independent of gross colony morphology which can exhibit phenotypic plasticity with depth and negate any effects of larger scale optical factors, reflectance measurements were taken within $\sim 1 \mathrm{~cm}$ from the surface of the coral (and Spectralon). At this scale of measurement, the surface of the skeleton is effectively flat and was assumed to scatter light equally well in all directions (Lambertian reflector, Enriquez et al. 2005). For each single measurement of $R$, the operator pointed the collecting tip of the fiber optic cable at the target on the coral and triggered acquisition of the spectrum by pressing a button on the palmtop. Immediately thereafter, the operator pointed the collecting tip at a Spectralon diffuse reflectance target (same depth as the target point on the coral) and triggered the storage of its spectrum. In this manner, both spectra could be acquired within 1 to $2 \mathrm{~s}$. Because the spectrometer was a 12-bit system with limited dynamic response, we used a $10 \%$ reflectance Spectralon so that measured light intensity from the coral and the Spectralon were of the same order (coral $R$ averages near $10 \%$; Hochberg et al. 2004), thus maximizing the measurable coral signal. To ensure a constant ambient light field between the 2 measurements, the Spectralon was placed immediately adjacent to the target point on the coral, and the operator's position was held constant for the 1 to $2 \mathrm{~s}$ required for the measurements. If light flashes due to wave focusing were obvious at the time of sampling, we shaded both the coral and Spectralon from direct light so that they were illuminated only by the ambient diffuse light field. For reflectance measurements of indoor aquarium samples, incandescent lights were used to help illuminate the corals. Spectra were acquired in units of digital counts.
All spectra were corrected for baseline electrical signal, then $R$ was calculated as the ratio of digital counts measured over the coral to the digital counts measured over the Spectralon, corrected to $100 \%$ reflectance, for each pair of measurements. $R$ was linearly interpolated to $1 \mathrm{~nm}$ intervals over the wavelength range 400 to $700 \mathrm{~nm}$, and the result was filtered using the Savitsky-Golay method (Savitzky \& Golay 1964, Steinier et al. 1972). For each point from which pigment samples would be taken ( $R$ was measured prior to tissue sampling), 10 to 20 replicate $R$ values were measured and averaged for combined analysis with the pigment data. Thus, the $R$ values used were both time-averaged (20 to $60 \mathrm{~s}$ ) and areaaveraged $\left(\sim 10 \mathrm{~cm}^{2}\right)$.

For thin plate corals, some light may travel downward through the colony, reflect from the background, and then travel upward through the colony. Thus, the methods detailed above actually provide apparent reflectance $R_{\text {measured, }}$ which is the light reflected from the coral plus the light passing through the coral, reflecting from the background, then passing through the coral again: $R_{\text {measured }}=R_{\text {coral }}+2 \times$ $T_{\text {coral }} \times R_{\text {background }} \times\left(1-R_{\text {coral }}\right)$, where $T_{\text {coral }}$ is the proportional transmittance of light through the coral. If $T_{\text {coral }}$ is low and/or $R_{\text {background }}$ is low (i.e. near 0 ), the difference between apparent reflectance and actual coral reflectance is negligible: $R_{\text {measured }} \approx R_{\text {coral }}$.

$T_{\text {coral }}$ was measured for bare Leptoseris skeletons by fixing the positions of the fiber optic cable and the light source, then measuring the difference in light intensity with and without the skeleton placed directly over the detector. By using bare skeletons with tissue and pigments chemically removed, this $T_{\text {coral }}$ value represented a very conservative maximum value for a live coral with full pigmentation $\left(T_{\text {skeleton }} \gg T_{\text {live coral }}\right)$. The original live Leptoseris colonies were not available for these measurements. For thick Porites skeletons $(\gg 1 \mathrm{~cm}), T_{\text {coral }}$ was assumed to be zero.

\section{Skeletal absorption}

To investigate the potential, differential effects of small-scale $(<1 \mathrm{~mm})$ optical geometry on light harvesting, spectral absorbance $A$ was calculated from reflectance $R$ and transmission $T$ using the following relation: $A=1-R-T$. A representative set of deepwater Leptoseris colonies $(\mathrm{n}=11)$ with varying micromorphologies was chosen for spectral reflectance measurements (collected from 70 to $113 \mathrm{~m}$ in 2004-2009 via manned-submersible from the Au'au Channel). A representative set of shallow-water 
Porites lobata/lutea $(\mathrm{n}=6)$ was also chosen for spectral reflectance measurements (collected from $2 \mathrm{~m}$ in 2004). Coral pigments and tissue were removed from deep-water Leptoseris and shallow-water Porites skeletons using aforementioned bleaching methods. $R$ was measured for each skeleton using the same light source and background, and $A$ was calculated following the equation above, with $T_{\text {Leptoseris }}$ determined from the skeletons and $T_{\text {Porites }}=0$ (due to thickness of skeletons).

$R$ was also measured from opposing sides of a subset of the bleached, deep-water Leptoseris skeletons ( $\mathrm{n}=9$ ). Bleached skeletons which retained non-white discoloration or evidence of fouling or bioerosion on the underside were removed from this analysis. To control for variations in skeletal thickness and possible interference with transmitted light being reflected back through the skeleton, the paired measurements were located on the same micro-portion of the skeleton and placed on a uniform background (clean, opaque manila folder). The difference between these paired (top and bottom) measurements was calculated to determine the difference in absorptance. Assuming a uniform chemical composition and mineralogy of the coral skeleton, any absorptance difference would represent the effects of differential optical geometry of each side of the coral skeleton.

\section{RESULTS}

\section{Downwelling light}

Measurements of downwelling light attenuation with depth indicate that light penetrates very well into the clear, offshore waters overlying the mesophotic reefs in the main Hawai'ian Islands compared to other tropical locations (Fig. 2). Within the depth range of 68 to $113 \mathrm{~m}$ where deep-water Leptoseris was sampled, PAR was 3 to $11 \%$ of surface irradiance $\left[K_{\mathrm{d}}(\mathrm{PAR})=0.047 \mathrm{~m}^{-1}\right]$. The irradiance spectrum at depth was predominately blue (Fig. 3). In contrast, the irradiance spectrum in shallow, coastal waters included higher levels of green and yellow light (Fig. 3). Within the depth range of 2 to $15 \mathrm{~m}$ where shallow-water Porites was sampled, PAR was 41 to $90 \%$ of surface irradiance $\left[K_{\mathrm{d}}(\mathrm{PAR})=0.056 \mathrm{~m}^{-1}\right]$.

\section{Spectral reflectance and absorbance for live corals}

Spectral transmittance through bleached Leptoseris skeletons across all visible wavelengths

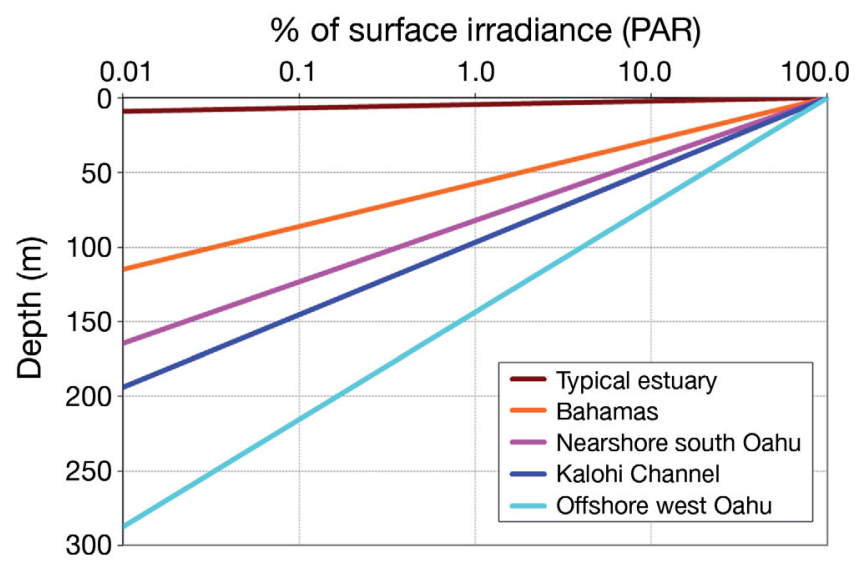

Fig. 2. A comparison of downwelling light attenuation (PAR) with depth for several water masses. Kalohi Channel measurements taken adjacent to mesophotic reefs where colonies were sampled. Data outside Hawai'i derived from Kirk (1994)

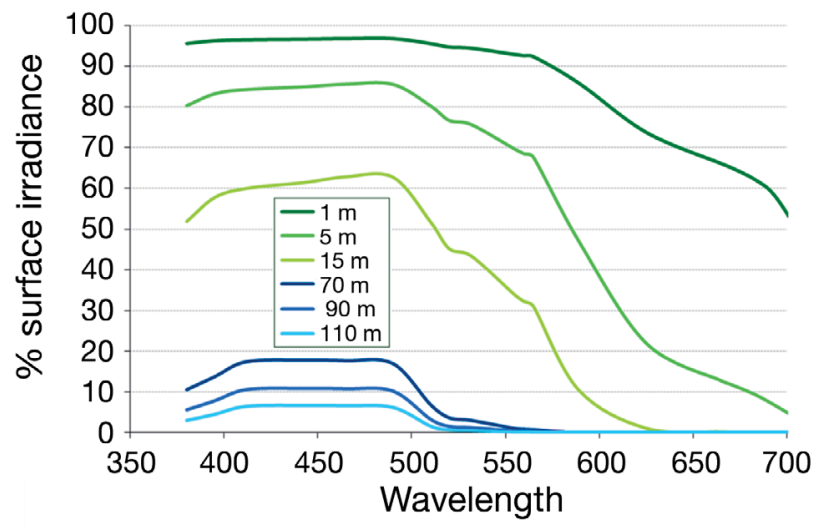

Fig. 3. Spectral irradiance as a percentage of surface irradiance at depths of 1 to $15 \mathrm{~m}$ in nearshore waters off southern O'ahu, Hawai'i adjacent to shallow-water coastal reefs dominated by Porites (lines in shades of green) and at depths of 70 to $110 \mathrm{~m}$ in the Kalohi Channel (lines in shades of blue) adjacent to deep-water reefs dominated by Leptoseris

(400-700 nm) was 1 to $3 \%$ which confirmed that the difference between apparent reflectance and live coral reflectance was negligible $\left(R_{\text {measured }} \approx R_{\text {coral }}\right)$ and that absorptance calculations for Leptoseris require a very small adjustment $(A=1-R-T)$. $T$ for live, pigmented Leptoseris is presumably much smaller than the $T$ for bleached skeletons $\left(\mathrm{T}_{\text {live coral }} \ll\right.$ $T_{\text {bleached skeleton }}$ ). Even with a conservative adjustment (i.e. $\mathrm{T}_{\text {live coral }}=2 \%$ ), the average $A$ of deep-water Leptoseris was very high (i.e. very low $R$ ) between 400 to $550 \mathrm{~nm}$, which corresponds to the wavelengths of available light at depth (Fig. 4). Leptoseris was less efficient at absorbing light at wavelengths longer than $550 \mathrm{~nm}$, but irradiance at these wavelengths is insignificant below depths of $\sim 70 \mathrm{~m}$ (Fig. 3). For the 


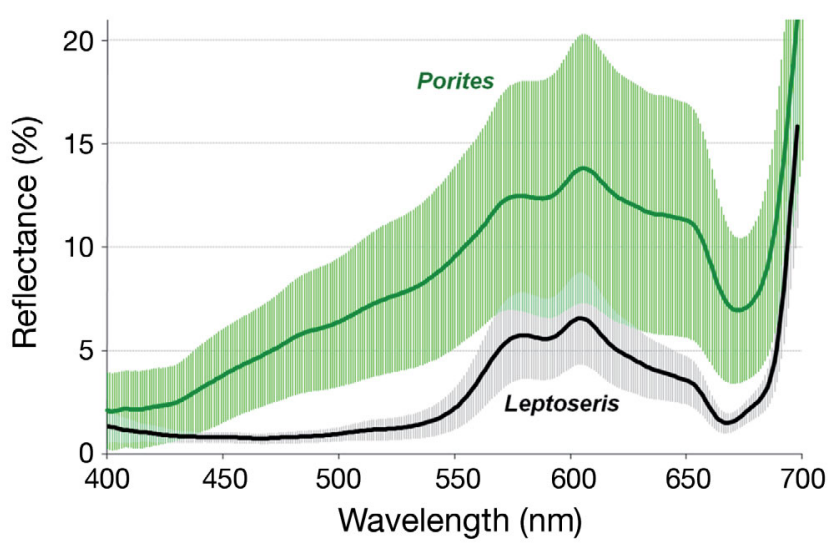

Fig. 4. Comparison of mean spectral reflectance between shallow-water Porites spp. (in green; $\mathrm{n}=36$ ) and deep-water Leptoseris spp. (in black; $\mathrm{n}=19$ ) in Hawai'i. Error bars represent standard deviation from the mean

samples of shallow-water Porites, the average spectral absorptance $\left(A=1-R-T\right.$, where $\left.T_{\text {Porites }}=0\right)$ was considerably lower than that of Leptoseris (Fig. 4).

While host pigments were not measured in this study, individual reflectance spectra of 4 Porites samples (data not shown) exhibited some evidence of host pigmentation via a departure from the typical triple-peaked spectra for a 'brown coral' (Hochberg et al. 2004). Individual reflectance spectra from only one Leptoseris sample (data not shown) exhibited a small possible contribution of host pigmentation to the overall shape of the reflectance spectra (slightly elevated reflectance at $515 \mathrm{~nm}$ ).

Measurements of bleached skeletons revealed that Leptoseris skeletons exhibited higher $A$ than Porites skeletons at longer wavelengths (>550 nm) but not at shorter wavelengths (Fig. 5). The top side of Leptoseris skeletons consistently exhibited $\sim 5 \%$ higher $A$ (lower $R$ ) than the underside of the same skeleton. The average difference was consistent across all wavelengths of visible light, although dispersion around the mean was relatively large (Fig. 6).

\section{Pigment measurements}

Areal photosynthetic pigment concentrations (chl $a$, chl $C_{2}$, peridinin, $\beta$-carotene, DDX, DTX, DINO) for live and cultured Leptoseris were consistently lower than those for shallow-water Porites (Fig. 7) (1-way ANOVA, all p-values < 0.021). The only exception to this pattern was chl $b$ which was significantly higher in Leptoseris than in Porites (1-way ANOVA, p-values < 0.001). In Leptoseris, contribution of

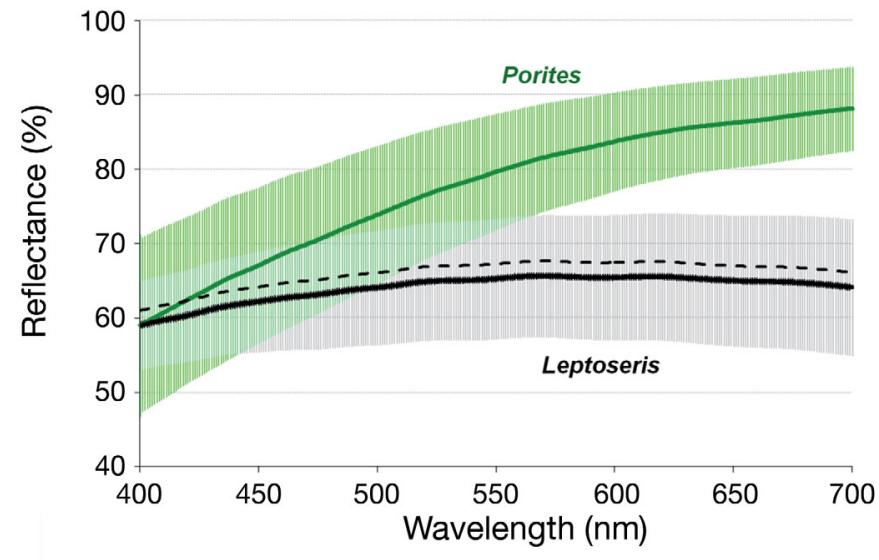

Fig. 5. Average spectral reflectance of bleached skeletons for Leptoseris ( $\mathrm{n}=11$ ) and Porites $(\mathrm{n}=6)$. Error bars represent standard deviation from the mean. Dashed black line represents Leptoseris spectral reflectance conservatively adjusted for $2 \%$ transmittance

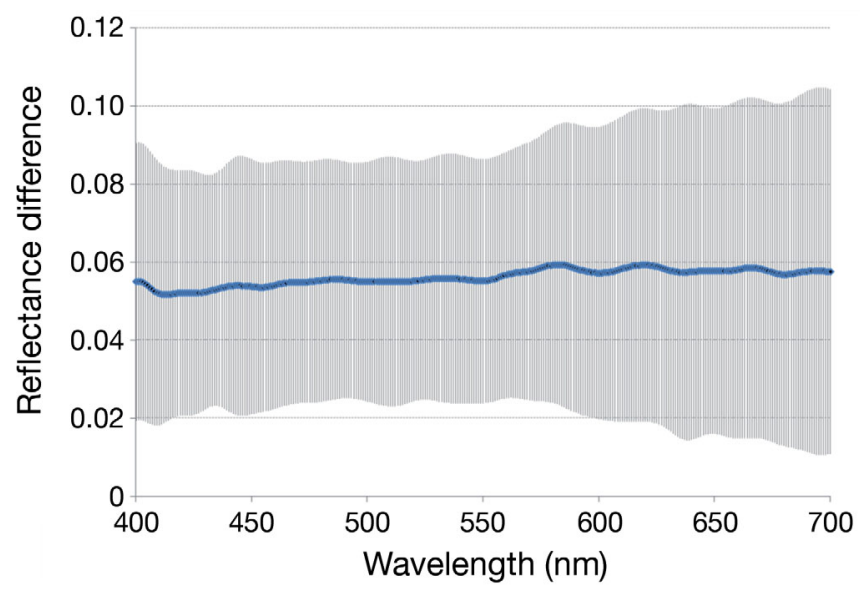

Fig. 6. Average difference in spectral reflectance for the top and bottom of bleached Leptoseris skeletons $(n=7)$. The spectral reflectance of the top of the skeleton was subtracted from the spectral reflectance of the bottom (which was always higher). Error bars represent standard deviation from the mean

chlorophyll a from endolithic algae was highly variable and accounted for an average of $26 \%$ (with a range of $1.6 \%$ to $68 \%$ ) of the total chlorophyll $a$. In order to compare dinoflagellate symbiont concentrations in the 2 coral species, the contribution of endolithic algal chlorophyll $a$ has been removed from these results.

The dinoflagellate endosymbiont pigment ratio for peridinin to chl a in deep-water Leptoseris was no different than those in shallow-water Porites (1-way ANOVA, p-value $=0.48$ ). However, the chl $c_{2}$ to $\operatorname{chl} a$ ratio was slightly higher in Porites compared to Leptoseris (1-way ANOVA, p-value $=0.05)$. The ratio of 


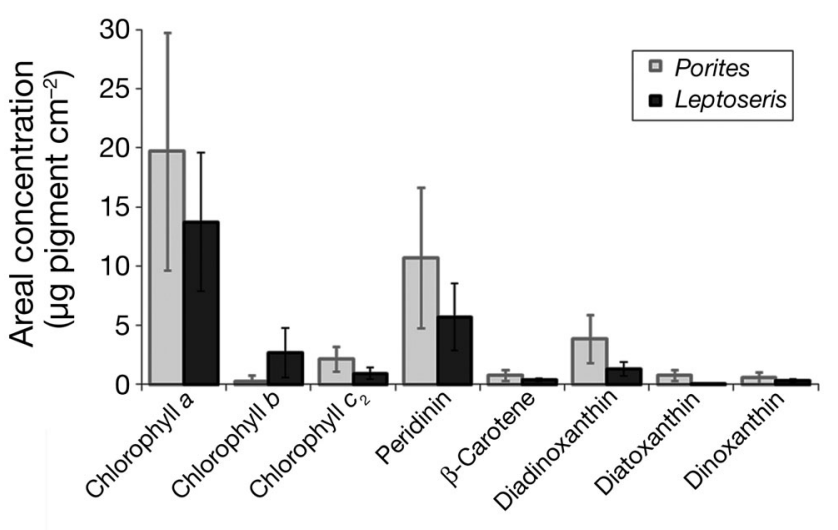

Fig. 7. Average areal photosynthetic pigment concentration (endosymbionts and endoliths) for deep-water Leptoseris $(n=19)$ and shallow-water Porites $(n=36)$ in Hawai'i. Error bars are standard deviation from the mean

(DDX + DTX) to chl a was significantly lower in Leptoseris than in Porites (1-way ANOVA, p-value < 0.001) (Fig. 8).

Within the 2 groups of Leptoseris samples (those frozen immediately after original collection and those sampled from the low intensity blue light aquarium culture), no statistically significant differences were found for any of the pigments (1-way ANOVA, all p-values $>0.34$ ) with one exception. Low concentrations of fucoxanthin (0.06 to $\left.0.41 \mu \mathrm{g} \mathrm{cm}^{-2}\right)$, which is characteristic of diatoms and prymnesiophytes but not dinoflagellates, were found in 7 of 10 aquarium samples. In contrast, only 3 of 9 Leptoseris samples immediately frozen following collection showed trace amounts of fucoxanthin $\left(0.07\right.$ to $\left.0.16 \mu \mathrm{g} \mathrm{cm}^{-2}\right)$.

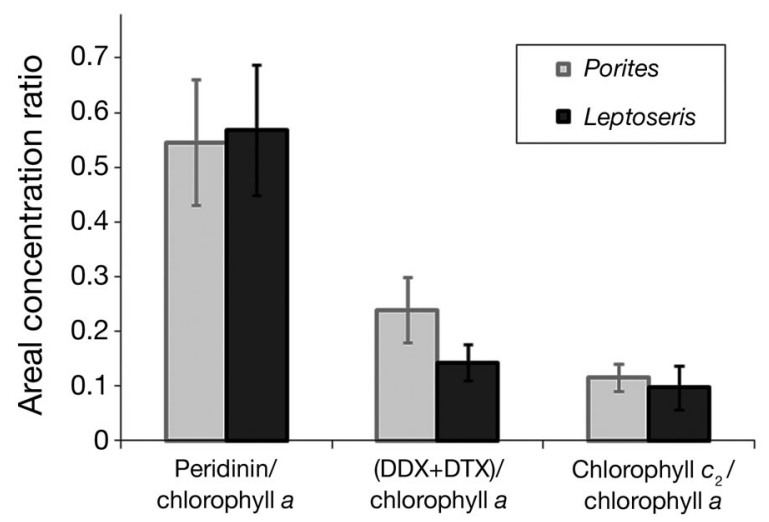

Fig. 8. Endosymbiont-corrected accessory pigment-tochlorophyll a ratios for deep-water Leptoseris $(\mathrm{n}=19)$ and shallow-water Porites $(\mathrm{n}=36)$ in Hawai'i. Error bars represent standard deviation from the mean. DDX = diadinoxanthin, DTX = diatoxanthin

\section{DISCUSSION}

The results of this study indicate that the lightharvesting properties of deep-water Leptoseris are superior to those of shallow-water Porites and appear to be well adapted to the spectral irradiance distribution at depth in off-shore waters in Hawai'i. At wavelengths between 400 to $550 \mathrm{~nm}$, deep-water Leptoseris exhibits $R 300$ to $400 \%$ lower than that of shallow-water Porites. Deep-water Leptoseris is less effective at absorbing light at wavelengths >550 nm, however, this portion of the spectrum is negligible on mesophotic reefs below $70 \mathrm{~m}$. The measurements of $K_{\mathrm{d}}(\mathrm{PAR})$ are consistent with other measurements made by the authors in coastal Hawai'i (unpubl. data) and confirm that offshore waters overlying these mesophotic reefs have higher water clarity than near-shore coastal waters overlying the fore reefs. This superior water clarity likely enables zooxanthellate corals to thrive at exceptional depths in Hawai'i.

Given the lower $A$ of shallow-water Porites compared to deep-water Leptoseris, the relative pigment concentrations are counterintuitive. Lower $A$ would be expected to be associated with lower areal pigment concentrations. However, the areal concentrations of photosynthetic and photo-protective pigments of shallow-water Porites were consistently higher than those of deep-water Leptoseris and are consistent with those reported from prior studies in Hawai'i (Cottone 1995, Kuffner 2005, Apprill et al. 2007)

In Hawai'i, the areal photosynthetic pigment concentrations for Porites compressa fluctuate seasonally and are inversely correlated to solar isolation (Kuffner 2005). This seasonal pattern is analogous to that reported for corals in other locations (Brown et al. 1999b, Fitt et al. 2000). If these same patterns hold true for our collection times, removal of seasonal effects would likely result in greater differences in pigment concentrations between Porites (April and August) and Leptoseris (October) than those observed. Following Kuffner (2005), pigment concentrations in April and August would be lower than those in October.

Reductions in photosynthetic pigment concentrations and concomitant absorption properties have been associated with various forms of environmental stress which cause a change in normal, ambient conditions (Glynn 1993, Brown 1997, Saxby et al. 2003). In particular, both acute and low level chronic thermal stresses have been implicated as causes of coral bleaching (Jokiel \& Coles 1990). In contrast, elevated nutrient concentrations have been demonstrated to 
increase areal pigment concentrations and concomitant absorption properties (Dubinsky et al. 1990). In general, shallow-water locations experience greater and more frequent fluctuations in environmental factors that influence pigments, such as elevated temperatures associated with bleaching, compared to off-shore, deep-water locations associated with the Leptoseris community studied here. By virtue of their location closer to the thermocline, mesophotic coral communities are exposed to elevated inorganic nutrient influx from internal tides compared to shallower corals (Drew 2001, Leichter et al. 2003). These conditions could act in concert to lower pigment concentrations in shallow-water corals and increase them in deep-water corals, diminishing the differences measured in this study.

An elevated peridinin to chl a ratio is an indicator of shade acclimation in dinoflagellates (IglesiasPrieto \& Trench 1994). However, this ratio was the same in deep-water Leptoseris as in shallow-water Porites. The in vivo absorption peak for chl $C_{2}$ (460 nm) is blue-shifted by $30 \mathrm{~nm}$ relative to photosynthetic carotenoids such as peridinin (490 nm) (Bidigare et al. 1990). An elevated $\mathrm{chl} c_{2}$ to $\mathrm{chl}$ a ratio has been associated with chromatic adaptation to the predominately blue spectrum at depth (Kaiser et al. 1993). However, this ratio was slightly lower in deepwater Leptoseris than in shallow-water Porites (Fig. 8). Diadinoxanthin (DDX) and diatoxanthin (DTX) are associated with photoprotective xanthophyll cycling in dinoflagellates, and an elevated ratio of (DDX + DTX) to chl a is an indicator of high light adaptation (Falkowski \& Raven 2007). As expected, this ratio was lower in deep-water Leptoseris than in shallow-water Porites (Fig. 8).

The concentrations of chl $b$ in deep-water Leptoseris indicate more endolithic algae compared to shallow-water Porites. Endoliths in Leptoseris also contribute significantly to total chl a concentrations and presumably to the overall spectral absorptance. Endolithic algae (Ostreobium queketttii) commonly inhabit low light regions of the coral skeleton below the coral tissue but are not considered a significant metabolic component in shallow-water corals (Magnusson et al. 2007, Ralph et al. 2007). This measurable difference may be an artifact caused by endolithic algae in the Porites skeletons living below the layer of skeleton that was physically sampled by coring. However, if this difference in relative abundance is real, endolithic algae which are extremely well adapted to low light environments may play a more important metabolic role in providing photosynthate to deep-water corals compared to shallow-water corals (Schlichter et al. 1997).

Some results and observations for deep-water Leptoseris in Hawai'i do not appear consistent with the photoadaptation mechanisms attributed to deepwater Leptoseris fragilis in the Red Sea (Fricke \& Schuhmacher 1983, Fricke \& Knauer 1986, Schlichter et al. 1986, Fricke et al. 1987, Schlichter et al. 1988, Schlichter \& Fricke 1991, Kaiser et al. 1993, Schlichter et al. 1994, Schlichter et al. 1997). Compared to L. fragilis in the Red Sea, the ratio of $\mathrm{chl} c_{2}$ to $\mathrm{chl} a_{\text {, }}$ and the chl $b$ concentration are much lower for Leptoseris in Hawai'i, suggesting that the roles of chl $C_{2}$ and endolithic algae may be less important for Hawai'ian Leptoseris spp. (Table 1).

Based on ultrastructural analyses and spectral measurements of Leptoseris fragilis in the Red Sea, Schlichter and colleagues proposed that host fluorescent proteins underlying zooxanthellae enhance photosynthesis under low-light conditions by transforming low wavelength light into longer wavelengths within the action spectra for photosynthesis (Schlichter et al. 1986, 1988, Schlichter \& Fricke 1991). However, subsequent experimental data from Caribbean corals demonstrated that fluorescent proteins do not enhance photosynthesis under low-light and fluorescence resonance energy transfer (FRET) from fluorescent proteins to chlorophyll does not occur in corals (reviewed by Lesser 2004, Dubinsky \& Falkowski 2011).

Table 1. Areal pigment concentrations and pigment ratios for Leptoseris spp. in Hawai'i and Leptoseris fragilis in the Red Sea. Abbreviations: zoox = zooxanthellae, endoliths = endolithic algae. Data are mean \pm SD except for Fricke et al. (1987) where data are range of mean values from 4 depth zones 100-135 m

\begin{tabular}{|c|c|c|c|c|c|c|c|}
\hline & Depth & $\begin{array}{c}\mathrm{Chl} \mathrm{a} \\
\left(\mu \mathrm{g} \mathrm{cm} \mathrm{cm}^{-2}\right)\end{array}$ & $\begin{array}{c}\text { Chl b } \\
\left(\mu \mathrm{cm}^{-2}\right)\end{array}$ & $\begin{array}{c}\mathrm{Chl} c_{2} \\
\left(\mu \mathrm{cm}^{-2}\right)\end{array}$ & $\mathrm{Chl} \mathrm{a/chl} C_{2}$ & $\begin{array}{l}\text { Peridinin } \\
\left(\mu \mathrm{cm}^{-2}\right)\end{array}$ & Reference \\
\hline Hawaii, zoox + endoliths & $68-110 \mathrm{~m}$ & $13.7 \pm 5.9$ & $2.6 \pm 2.1$ & $0.9 \pm 0.5$ & $16.5 \pm 5.9$ & $5.7 \pm 2.8$ & This study \\
\hline Red Sea, zoox + endoliths & $100-135 \mathrm{~m}$ & $1.2-4.3$ & $\mathrm{n} / \mathrm{a}$ & $1.0-2.1$ & $1.7-2.4$ & $\mathrm{n} / \mathrm{a}$ & Fricke et al. (1987) \\
\hline Red Sea, zoox only & $100-120 \mathrm{~m}$ & $1.59 \pm 0.86$ & $\mathrm{n} / \mathrm{a}$ & $1.96 \pm 1.21$ & $\mathrm{n} / \mathrm{a}$ & $0.28 \pm 0.16$ & $\begin{array}{l}\text { Kaiser et al. (1993), } \\
\text { Schlichter et al. (1997) }\end{array}$ \\
\hline Red Sea, endoliths only & $100-120 \mathrm{~m}$ & $6.19 \pm 1.81$ & $4.49 \pm 1.90$ & $\mathrm{n} / \mathrm{a}$ & $\mathrm{n} / \mathrm{a}$ & $\mathrm{n} / \mathrm{a}$ & Schlichter et al. (1997) \\
\hline
\end{tabular}


While green fluorescent pigments in some deepwater Leptoseris colonies in Hawai'i are clearly visible in situ, their variable distributions across colonies within monospecific Leptoseris aggregations and within individual colonies appear inconsistent with a photoadaptive function. The lack of a measurable fluorescence peak in the reflectance spectrum of Leptoseris confirms that the fluorescence, while clearly visible (when illuminated with blue light 400-460 nm from a NightSea BE1 exciter filter and viewed through a blue-light barrier filter), is not a major optical property. If green fluorescent proteins were energetically coupled to photosynthetic pigments, their green fluorescence would not be visible due to the energy transfer to chlorophylls which exhibit red fluorescence (Dubinsky \& Falkowski 2011).

The findings from this study suggest that deepwater Leptoseris in Hawai'i possess superior lightharvesting capabilities compared to dominant shallow-water reef building corals. However, these superior capabilities are not due to elevated pigment concentrations or chromatic adaptation typically associated with acclimation to low light. These results confirm the importance of increased photosynthetic efficiency in an energy-limited environment. Increased cellular pigmentation is a self-limiting strategy because it not only requires more energetic investment in photosynthetic machinery but also increases mutual self-shading of pigment molecules and thereby decreases the in vivo spectral average optical absorbance cross section of chl a $\left(a^{*}\right)$ (Dubinsky \& Stambler 2009). While increases in cellular pigmentation will incrementally increase light utilization and quantum yield of photosynthesis $(\Phi)$, the reduction in $a^{*}$ will eventually reduce photosynthetic efficiency ( $\alpha=\Phi a^{*}$ ) in the lower photic zone (Dubinsky \& Stambler 2009). Skeletal morphology designed to scatter light through the coral tissue combined with pigment packaging (efficient spatial positioning of light harvesting centers) may be the key to the unique photo-ecology of these deep-water zooxanthellate corals.

As reported by Enriquez et al. (2005), coral skeletons reflect light that is not absorbed during its initial pass through the coral tissue. The coral skeleton scatters light at multiple angles which increase the average path length and therefore the amount of coral tissue through which light must travel prior to escaping. Low angle and multiple scattering of incident light can increase light harvesting efficiency without a change in pigment concentrations. The diversity of micro-scale skeletal morphologies and geometries creates variations in the efficiency with which coral skeletons scatter and 'trap' light (Enriquez et al. 2005).

Elevated photosynthetic efficiency from light scattering is a concept utilized in other photosynthetic organisms and environments. At a community level of any aggregation of calcified photosynthetic taxa (e.g. meadow of Halimeda, bloom of coccolithophores, etc.), multiple scattering of light not initially absorbed by photosynthetic pigments can increase overall photosynthetic efficiency by reflecting unused light to nearby organisms. Similarly, reef plants growing on top of reflective substrata (e.g. carbonate reef or white sand) would receive analogous benefits. In contrast, for non-calcified photosynthetic taxa growing on less reflective substrata (e.g. basalt or clay silt), more light would be absorbed by the substrata or in the case of epipelagic phytoplankton, more light would be transmitted through the phytoplankton community to deeper depths extending the depth of the photic zone.

Assuming that Porites and Leptoseris skeletons share the same chemical composition (i.e. calcium carbonate) and same crystal structure (i.e. aragonite), the higher $A$ of bleached Leptoseris skeletons suggests that micro-scale optical geometry increases the interaction between light and the skeleton, as compared to Porites. An alternate explanation is that Leptoseris skeletons may contain a higher residual level of organic matter within the skeletal matrix than Porites skeletons. However, the consistently higher $A$ of the top versus the relatively featureless underside of Leptoseris skeletons provides further evidence for enhanced light capture from microscale optical geometry. The more pronounced and significant difference in $A$ between bleached skeletons for the 2 genera at higher wavelengths (Fig. 5) further suggests that Leptoseris skeletal structure enhances light capture: Porites skeletal $R$ follows the shape and magnitude of $R$ for pure calcium carbonate, generally increasing with wavelength, while Leptoseris skeletal $R$ is spectrally flat (Gaffey 1986, Maritorena et al. 1994).

An examination of Porites and Leptoseris skeletons reveals contrasting characteristics which may explain a differential efficiency of light absorbance. Massive reef-building corals in shallow-water must form robust skeletons which can withstand large hydrodynamic forces. Porites skeletons grow both outward and upward. The surface area of Porites skeletons consists of shallow calices and porous coenosteum (Veron 2000). These features would effectively scatter light at multiple angles but would 
not necessarily 'trap' light within the skeleton (internal scattering) on a consistent basis. However, in well-lit shallow waters, light energy is less limiting and other skeletal functions (e.g. durability, upward growth, and protecting greater tissue biomass) likely dictate the skeletal architecture for shallow-water corals like Porites spp.

In contrast, Leptoseris skeletons in the lower photic zone $(>80 \mathrm{~m})$ are exclusively flat plates which grow radially outwards, but not upwards. This growth form allows formation of uniform and delicate structures such as deep and narrow septo-costae oriented perpendicular to incident light and sometimes forming convex cavities (Fig. 9). This geometric design could increase internal scattering of light between adjacent septo-costae causing light to pass through the coral tissue multiple times and increase the probability of light capture by pigments within the tissue. The morphology of some of the deepest Leptoseris spp. are horizontal plates primarily composed of parallel septo-costae with very few, widely spaced, flat calices. Such a skeletal design could be very effective at trapping light uniformly across the entire skeleton. Even though deep-water zooxanthellate corals may have less tissue biomass per unit surface

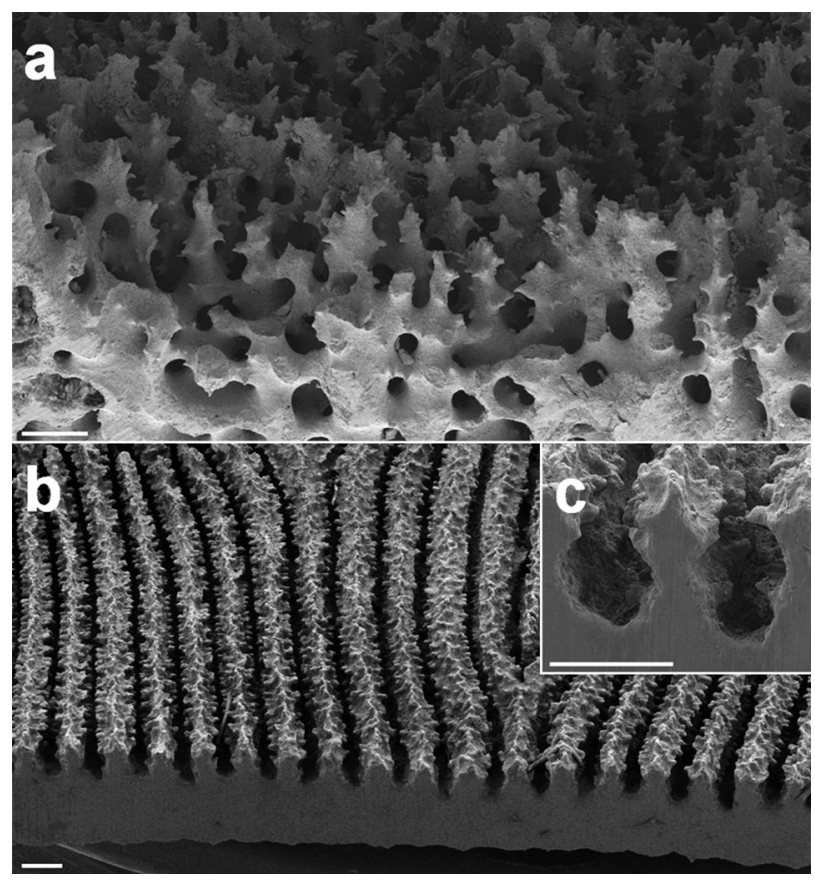

Fig. 9. Scanning electron micrographs of (a) Porites and (b \& c) Leptoseris skeletons. Cross section of Porites reveals a porous skeleton with an irregular geometry, whereas cross section of Leptoseris skeleton reveals parallel, concave costae forming deep convex valleys. All scale bars $=200 \mu \mathrm{m}$ area (Dustan 1979, Anthony \& Hoegh-Guldberg 2003) and significantly lower areal concentrations of photosynthetic pigments, we hypothesize that their coral skeletons may have superior light-trapping properties by virtue of their micro-scale geometry. For deep-water zooxanthellate corals like Leptoseris, this skeletal design likely increases the average path length of light within their tissue to be much greater than that of their shallow-water counterparts thereby enabling superior light harvesting with less pigment per unit area.

Acknowledgements. This research was funded in part by the Hawai'i Undersea Research Laboratory (HURL), the Western Pacific Regional Fishery Management Council, and Hawaii Pacific University Trustees' Scholarly Endeavors Program. Special thanks to S. Christensen for HPLC assistance; G. Susner for assistance with PRR measurements; and J. Crow, A. Rossiter, R. Klobuchar, and the Waikiki Aquarium staff for logistical support; and J. Maragos, C. Veron, and Z. Dinesen for assistance with Leptoseris taxonomy.

\section{LITERATURE CITED}

Alamaru A, Loya Y, Brokovich E, Yam R, Shemesh A (2009) Carbon and nitrogen utilization in two species of Red Sea corals along a depth gradient: insights from stable isotope analysis of total organic material and lipids. Geochim Cosmochim Acta 73:5333-5342

> Anthony KRN, Hoegh-Guldberg O (2003) Variation in coral photosynthesis, respiration and growth characteristics in contrasting light microhabitats: an analogue to plants in forest gaps and understoreys. Funct Ecol 17:246-259

Anthony KRN, Hoogenboom MO, Connolly SR (2005) Adaptive variation in coral geometry and the optimization of internal colony light climates. Funct Ecol 19:17-26

Apprill AM, Bidigare RR, Gates RD (2007) Visibly healthy corals exhibit variable pigment concentrations and symbiont phenotypes. Coral Reefs 26:387-397

> Baker AC (2003) Flexibility and specificity in coral-algal symbiosis: diversity, ecology, and biogeography of Symbiodinium. Annu Rev Ecol Evol Syst 34:661-689

Bidigare RR, Ondrusek ME, Morrow JH, Kiefer DA (1990) In vivo absorption properties of algal pigments. Proc. SPIE Ocean Opt X 1302:290-302

Birkeland C (1997) Life and death of coral reefs. Kluwer Academic Publishers, Boston, MA

> Brown B (1997) Coral bleaching: causes and consequences. Coral Reefs 16:S129-138

> Brown BE, Ambarsari I, Warner ME, Fitt WK, Dunne RP, Gibb SW, Cummings DG (1999a) Diurnal changes in photochemical efficiency and xanthophyll concentrations in shallow water reef corals: evidence for photoinhibition and photoprotection. Coral Reefs 18:99-105

> Brown BE, Dunne RP, Ambarsari I, LeTisser MDA, Satapoomin U (1999b) Seasonal fluctuations in environmental factors and variations in symbiotic algae and chlorophyll pigments in four Indo-Pacific coral species. Mar Ecol Prog Ser 191:53-69

Cottone MC (1995) Coral pigments: quantification using HPLC and detection by remote sensing. MSc thesis, University of Washington 
Dinesen ZD (1983) Shade-dwelling corals of the Great Barrier Reef. Mar Ecol Prog Ser 10:173-185

Dollar SJ (1982) Wave stress and coral community structure in Hawaii. Coral Reefs 1:71-81

Drew AE (2001) Ocean nutrients to sediments banks via tidal jets and Halimeda meadows. In: Wolanski E (ed) Oceanographic processes of coral reefs: physical and biological links in the Great Barrier Reef. CRC Press, Florida, p 255-267

Dubinsky Z, Falkowski P (2011) Light as a source of information and energy in zooxanthellate corals. In: Dubinsky Z, Stambler N (eds) Coral reefs: an ecosystem in transition. Springer, Dordrecht, p 107-118

Dubinsky Z, Stambler N (2009) Photoacclimation processes in phytoplankton: mechanisms, consequences, and applications. Aquat Microb Ecol 56:163-176

Dubinsky Z, Stambler N, Ben-Zion M, McCloskey LR, Muscatine L, Falkowski PG (1990) The effect of external nutrient resources on the optical properties and photosynthetic efficiency of Stylophora pistillata. Proc R Soc Lond Ser B Biol Sci 239:231-246

Dustan P (1979) Distribution of zooxanthellae and photosynthetic chloroplast pigments of the reef-building coral Montastrea annularis Ellis and Solander in relation to depth on a West Indian coral reef. Bull Mar Sci 29: 79-95

> Dustan P (1982) Depth-dependent photoadaption by zooxanthellae of the reef coral Montastrea annularis. Mar Biol 68:253-264

Einbinder S, Mass T, Brokovich E, Dubinsky Z, Erez J, Tchernov D (2009) Changes in morphology and diet of the coral Stylophora pistillata along a depth gradient. Mar Ecol Prog Ser 381:167-174

Enriquez S, Méndez E, Iglesias-Prieto R (2005) Multiple scattering on coral skeletons enhances light absorption by symbiotic algae. Limnol Oceanogr 50:1025-1032

Falkowski PG, Dubinsky Z (1981) Light-shade adaptation of Stylophora pistillata, a hermatypic coral from the Gulf of Eilat. Nature 289:172-174

Falkowski PG, Laroche J (1991) Acclimation to spectral irradiance in algae. J Phycol 27:8-14

Falkowski PG, Raven JA (2007) Aquatic photosynthesis. Princeton University Press, Princeton

Falkowski PG, Jokiel PL, Kinsey RR (1990) Irradiance and corals. In: Dubinsky Z (ed) Ecosystems of the world 25: coral reefs. Elsevier Science Publishing, Amsterdam, p 89-107

> Fitt WK, McFarland FK, Warner ME, Chilcoat GC (2000) Seasonal patterns of tissue biomass and densities of symbiotic dinoflagellates in reef corals and relation to coral bleaching. Limnol Oceanogr 45:677-685

Fletcher C, Bochicchio C, Conger C, Engels $M$ and others (2008) Geology of Hawaii reefs. In: Riegl B, Dodge R (eds) Coral reefs of the USA. Springer, p 435-488

Fricke HW, Knauer B (1986) Diversity and spatial pattern of coral communities in the Red Sea upper twilight zone. Oecologia 71:29-37

Fricke HW, Schuhmacher H (1983) The depth limits of Red Sea stony corals: an ecophysiological problem (a deep diving survey by submersible). PSZNI: Mar Ecol 4: 163-194

Fricke HW, Vareschi E, Schlichter D (1987) Photoecology of the coral Leptoseris fragilis in the Red Sea twilight zone (an experimental study by submersible). Oecologia 73: $371-381$
Gaffey SJ (1986) Spectral reflectance of carbonate minerals in the visible and near-infrared (0.35-2.55 microns): calcite, aragonite, and dolomite. Am Mineral 71:151-162

Gage J (2003) Food inputs, utilization, carbon flow and energetics. In: Tyler PA (ed) Ecosystems of the deep oceans (Ecosystems of the world), Vol. 28. Elsevier, Amsterdam, p 313-380

> Glynn PW (1993) Coral reef bleaching: ecological perspectives. Coral Reefs 12:1-17

Grigg RW (1983) Community structure, succession and development of coral reefs in Hawaii. Mar Ecol Prog Ser 11:1-14

> Grigg RW (2006) Depth limit for reef building corals in the Au'au Channel, S.E. Hawaii. Coral Reefs 25:77-84

> Hinderstein LM, Marr JCA, Martinez FA, Dowgiallo MJ and others (2010) Theme section on 'Mesophotic coral ecosystems: characterization, ecology, and management.'. Coral Reefs 29:247-251

Hochberg EJ, Atkinson MJ (2000) Spectral discrimination of coral reef benthic communities. Coral Reefs 19:164-171

Hochberg EJ, Atkinson MJ, Apprill A, Andrefouet S (2004) Spectral reflectance of coral. Coral Reefs 23:84-95

- Hochberg EJ, Apprill AM, Atkinson MJ, Bidigare RR (2006) Bio-optical modeling of photosynthetic pigments in corals. Coral Reefs 25:99-109

> Hoogenboom MO, Connolly SR, Anthony KRN (2008) Interactions between morphological and physiological plasticity optimize energy acquisition in corals. Ecology 89: 1144-1154

Hoogenboom MO, Connolly SR, Anthony KRN (2009) Effects of photoacclimation on the light niche of corals: a process-based approach. Mar Biol 156:2493-2503

- Huston M (1985) Variation in coral growth rates with depth at Discovery Bay, Jamaica. Coral Reefs 4:19-25

Iglesias-Prieto R, Trench RK (1994) Acclimation and adaptation to irradiance in symbiotic dinoflagellates. I. Responses of the photosynthetic unit to changes in photon flux density. Mar Ecol Prog Ser 113:163-175

Jeffrey S, Haxo H (1968) Photosynthetic pigments of symbiotic dinoflagellates (zooxanthellae) from corals and clams. Biol Bull 135:149-165

Jokiel P, Coles S (1990) Response of Hawaiian and other Indo-Pacific reef corals to elevated temperature. Coral Reefs 8:155-162

> Kahng SE, Kelley C (2007) Vertical zonation of habitat forming benthic species on a deep photosynthetic reef (50-140 $\mathrm{m}$ ) in the Au'au Channel, Hawaii. Coral Reefs 26:679-687

Kahng SE, Maragos JE (2006) The deepest zooxanthellate, scleractinian corals in the world? Coral Reefs 25:254

> Kahng SE, Garcia R, Spalding HL, Brokovich E and others (2010) MCE: Community ecology of mesophotic coral reef ecosystems. Coral Reefs 29:255-275

Kaiser P, Schlichter D, Fricke HW (1993) Influence of light on algal symbionts of the deep coral Leptoseris fragilis. Mar Biol 117:45-52

> Kaniewska P, Anthony KRN, Hoegh-Guldberg O (2008) Variation in colony geometry modulates internal light levels in branching corals, Acropora humilis and Stylophora pistillata. Mar Biol 155:649-660

Kirk JTO (1994) Light and photosynthesis in aquatic ecosystems. Cambridge University Press, New York, NY

Kohler KE, Gill SM (2006) Coral Point Count with Excel extensions (CPCe): a Visual Basic program for the determination of coral and substrate coverage using random point count methodology. Comput Geosci 32:1259-1269 
Kuffner IB (2005) Temporal variation in photosynthetic pigments and UV-absorbing compounds in shallow populations of two Hawaiian reef corals. Pac Sci 59:561-580

Kühl M, Cohen Y, Dalsgaard T, Jorgensen B, Revsbech N (1995) Microenvironment and photosynthesis of zooxanthellae in scleractinian corals studied with microsensors for O2, pH and light. Mar Ecol Prog Ser 117:159-172

Kühlmann D (1983) Composition and ecology of deep-water coral associations. Helgol Mar Res 36:183-204

Leichter J, Stewart H, Miller S (2003) Episodic nutrient transport to Florida coral reefs. Limnol Oceanogr 48: 1394-1407

Lesser MP (2000) Depth-dependent photoacclimatization to solar ultraviolet radiation in the Caribbean coral Montastraea faveolata. Mar Ecol Prog Ser 192:137-151

Lesser M (2004) Experimental biology of coral reef ecosystems. J Exp Mar Biol Ecol 300:217-252

Lesser MP, Slattery M, Stat M, Ojimi M, Gates RD, Grottoli A (2010) Photoacclimatization by the coral Montastraea cavernosa in the mesophotic zone: light, food, and genetics. Ecology 91:990-1003

Magnusson SH, Fine M, Kuhl M (2007) Light microclimate of endolithic phototrophs in the scleractinian corals Montipora monasteriata and Porites cylindrica. Mar Ecol Prog Ser 332:119-128

Maragos JE, Jokiel P (1986) Reef corals of Johnston Atoll: one of the world's most isolated reefs. Coral Reefs 4: $141-150$

Maritorena S, Morel A, Gentili B (1994) Diffuse reflectance of oceanic shallow waters: influence of water depth and bottom albedo. Limnol Oceanogr 39:1689-1703

Mass T, Einbinder S, Brokovich E, Shashar N, Vago R, Erez J, Dubinsky Z (2007) Photoacclimation of Stylophora pistillata to light extremes: metabolism and calcification. Mar Ecol Prog Ser 334:93-102

Muscatine L (1990) The role of symbiotic algae in carbon and energy flux in coral reefs. In: Dubinsky Z (ed) Ecosystems of the world 25: coral reefs. Elsevier Science Publishing, Amsterdam, p 75-87

Muscatine L, Porter J, Kaplan I (1989) Resource partitioning by reef corals as determined from stable isotope composition. Mar Biol 100:185-193

Ralph PJ, Larkum AWD, Kuhl M (2007) Photobiology of endolithic microorganisms in living coral skeletons: 1. Pigmentation, spectral reflectance and variable chloro-

Editorial responsibility: Matthias Seaman, Oldendorf/Luhe, Germany phyll fluorescence analysis of endoliths in the massive corals Cyphastrea serailia, Porites lutea and Goniastrea australensis. Mar Biol 152:395-404

> Rooney J, Donham E, Montgomery A, Spalding H and others (2010) Mesophotic coral ecosystems in the Hawaiian Archipelago. Coral Reefs 29:361-367

> Savitzky A, Golay MJE (1964) Smoothing and differentiation of data by simplified least squares procedures. Anal Chem 36:1627-1639

Saxby T, Dennison WC, Hoegh-Guldberg O (2003) Photosynthetic responses of the coral Montipora digitata to cold temperature stress. Mar Ecol Prog Ser 248:85-97

Schlichter D, Fricke HW (1991) Mechanisms of amplifiction of photosynthetically active radiation in the symbiotic deep-water coral Leptoseris fragilis. Hydrobiologia 216/ 217:389-394

> Schlichter D, Fricke H, Weber W (1986) Light harvesting by wavelength transformation in a symbiotic coral of the Red Sea twilight zone. Mar Biol 91:403-407

Schlichter D, Fricke H, Weber W (1988) Evidence for PARenhancement by reflection, scattering and fluorescence in the sym-biotic deep water coral Leptoseris fragilis. Endocytol C Res 5:83-94

Schlichter D, Meier U, Fricke H (1994) Improvement of photosynthesis in zooxanthellate corals by autofluorescent chromatophores. Oecologia 99:124-131

Schlichter D, Kampmann H, Conrady S (1997) Trophic potential and photoecology of endolithic algae living within coral skeletons. PSZNI: Mar Ecol 18:299-317

Sosik HM (1999) Storage of marine particulate samples for light-absorption measurements. Limnol Oceanogr 44: 1139-1141

Stambler N, Dubinsky Z (2007) Marine phototrophs in the twilight zone. In: Seckbach J (ed) Algae and cyanobacteria in extreme environments. Springer, Dordrecht, p 79-97

Steinier J, Termonia Y, Deltour J (1972) Comments on smoothing and differentiation of data by simplified least square procedure. Anal Chem 44:1906-1909

Veron JEN (2000) Corals of the World. Australian Institute of Marine Science, Townsville

> Wyman KD, Dubinsky Z, Porter JW, Falkowski PG (1987) Light absorption and utilization among hermatypic corals: a study in Jamaica, West Indies. Mar Biol 96: 283-292

Submitted: January 28, 2010; Accepted: February 6, 2012 Proofs received from author(s): May 5, 2012 